\title{
Rationally Agential Pleasure? A Kantian Proposal
}

\author{
Keren Gorodeisky \\ Pleasure: a History, ed. Lisa Shapiro (Oxford University Press, 2018) \\ PENULTIMATE VERSION
}

Reading without enjoyment is stupid.

(John Williams)

What can we learn, if at all, from Kant's view of pleasure? Many, even some of Kant's most faithful advocates, retort: "nothing", for they take this view of his to represent one of the greatest weaknesses in his thought. Here, for example, is Christine Korsgaard: "Kant ... denies that pleasure and pain tell us anything about anything $[\ldots]$ Kant thinks that pleasure and pain are mere feelings, that they are, to put the point a little bluntly, stupid." In the realm of aesthetics too, interpreting Kant's understanding of pleasure, perhaps not as "stupid," but nonetheless as a "mere sensation"—a passive, nonintentional, opaque, and only quantitatively differentiated state — has reigned in the literature until recently. ${ }^{2}$

\footnotetext{
${ }^{1}$ Christine M. Korsgaard, "From Duty and for the sake of the Noble," in Aristotle, Kant and the Stoics, eds. S. Engstrom \& J. Whiting (Cambridge: Cambridge University Press, 1996), 203-36.

${ }^{2}$ For Paul Guyer's famous interpretation of aesthetic pleasure as non-intentional and opaque, see his Kant and the Claims of Taste (Cambridge: Cambridge University Press, 1979), chap. 3. For criticisms of Guyer's view, see Henry Allison, Kant's Theory of Taste (Cambridge: Cambridge University Press, 2001) chaps. 2 and 3 and "Reply to the Comments of Longuenesse and Ginsborg," Inquiry 46:2(2003), 182-194; Hannah Ginsborg, The Normativity of Nature (Oxford, UK: OUP, 2015); Rachel Zuckert, Kant on Beauty and Biology (Cambridge: Cambridge University Press, 2007), chap. 6; and Joseph Cannon "The Intentionality of Judgments of Taste in Kant's Critique of Judgment," in The Journal of Aesthetics and Art Criticism, 66:1 (2008), 53-66.
} 
In this paper, I offer a rebuttal of this line of interpretation by presenting the rational character of the pleasure one takes when making judgments of taste. ${ }^{3}$ Kant's account of the pleasures we take in the good and in the beautiful is at odds both with this line of interpretation, and with a standard contemporary account of pleasure as either passive, non-object-directed and opaque or as cognitive by virtue of the beliefs or desires that accompany it. ${ }^{4}$ Kant's account offers a model for thinking about pleasure as a conscious state that is itself capable of responsiveness to reasons. My main aim in this paper is to articulate the distinctive way in which aesthetic pleasure, on his view, though a felt, affective state, is itself an exercise of rationality.

However aptly the unappealing understanding of pleasure as either "stupid" or, at best, a "mere sensation" might apply to Kant's earlier conception, Kant's 1787 discovery

\footnotetext{
${ }^{3}$ For other interpretations that stress the non-passive, intentional and even normative nature of aesthetic pleasure, but not its peculiar rational nature see Allison, Kant's Theory of Taste, Ginsborg, The Normativity of Nature, Zuckert, Beauty and Biology and Joseph Tinguely, "Kantian Meta-Aesthetics and the Neglected Alternative," British Journal of Aesthetics 50:2(2013), 211-235. In addition to this difference regarding the rationality of aesthetic pleasure, my view differs from these in the following ways: it differs from Zuckert's in that she denies that either the pleasure or its principle is normative (Zuckert, Beauty and Biology, 27178). While Allison emphasizes the normative nature of the judgment of taste, his account seems to foreclose the possibility that the pleasure in the beautiful itself is normative. (Ginsborg offers a detailed criticism of Allison's view in this respect in The Normativity of Nature.) While Ginsborg does regard the pleasure as internal to the judgment and stresses its normativity, as I do, my view differs from her primarily in that, on my reading, aesthetic judgment and pleasure are (1) about the beauty of the objects judged, and (2) explained by the distinctive logical form of aesthetic judgment. The picture I portray here comes closest to Tinguely, especially in stressing the active nature of aesthetic pleasure, but he explains that nature in terms of the pleasure's discriminatory ability while I explain it in terms of its responsiveness to reasons. Moreover, I suspect that, on his picture, the rationality of aesthetic pleasure does not categorically differ from the rationality of belief and action, a difference that is the heart of my view in A Matter of Form: The Significance of Kant's Judgment of Taste (ms.).

${ }^{4}$ For the sake of simplicity, I call the "pleasure in the beautiful" for the most part of this paper "aesthetic pleasure," even though Kant uses the term "aesthetic" to refer both to judgments of beauty, sublimity and fine arts and to judgments of agreeableness. His technical term for the former is "aesthetic judgment of reflection" and for the latter, "aesthetic judgment of sense" (FI, 20:224). Nevertheless, though it is a "pathologically conditioned satisfaction" (Critique of the Power of Judgment, 5:209), the pleasure in the agreeable is as (practical as it is aesthetic given its relation to the faculty of desire and to practical reason. This gives me further license to use the term "aesthetic pleasure" to refer to the pleasures of taste alone. While, for Kant, the pleasure in the sublime is as rational as the pleasures in beauty and fine art, it is more complex than the latter. Hence, my discussion in this paper is restricted to the pleasures in beauty and fine art.
} 
of the new a priori principle of the power of judgment - the power that he identifies as the intellectual part of the faculty of pleasure and displeasure - marks a significant shift in his view. From that time, Kant clearly and explicitly denies that all pleasures and displeasures are "mere sensations."

On my reading, rather than brute, opaque, atomic, and passive, even our sensory pleasures (the ones Kant calls "pleasures in the agreeable") are not merely animal pleasures, but always already human pleasures (for they are dependent for their very possibility as pleasures on the determination of practical reason-on the efficacy of the will, which is the faculty for practical cognition). ${ }^{5}$ In addition, and much more relevant to my purposes here, Kant insists that certain kinds of pleasure - the pleasure in the good and the pleasure in the beautiful—are rational pleasures insofar as they are conscious, complex states that are active not because they are produced 'at will,' but because they are affectively self-conscious, and capable of responsiveness to reasons, albeit they are responsive to categorically different kinds of reasons (moral and aesthetic reasons respectively). ${ }^{6}$ Aesthetic pleasure, particularly, is not only an intentional and

\footnotetext{
${ }^{5}$ For reasons of space, I cannot here expand on this claim, as I do in A Matter of Form: The Significance of Kant's Judgment of Taste (ms.). For a fine, detailed explanation of the relation between pleasures of the agreeable and practical reason, see Stephen Engstrom, The Form of Practical Knowledge: a Study of the Categorical Imperative (Cambridge, Mass: Harvard University Press, 2009).

${ }^{6}$ Even though both moral pleasure and aesthetic pleasure are exercises of rational agency, in this paper I focus on the latter. While the rational nature of moral pleasure is, for Kant, closely tied to this pleasure being a motivation for action, the rational nature of aesthetic pleasure is independent of desire and of any motivational structure of action. And yet, its responsiveness to reasons renders it rational and agential in the way I aim to establish and explain below. Aesthetic pleasure, then, is very well suited for explaining and highlighting the possible rational and agential, albeit non-motivational and non-desirative, nature of pleasure in general. On Kant's view of moral pleasure, see for example, Iain Morrisson, Kant and the Role of Pleasure in Moral Action (Athens, OH: Ohio University Press, 2008); Ido Geiger, "Rational Feelings and Moral Agency," Kantian Review, 16.2 (2011): 283-308; Carla Bagnoli, "Emotions and the Categorical Authority of Moral Reason," in Morality and the Emotions ed. Carla Bagnoli (Oxford: OUP, 2015); Erica Holberg, "The Importance of Pleasure in the Moral for Kant's Ethics" The Southern Journal of Philosophy (forthcoming). For a fresh and instructive collection of Kant's view of the emotions more generally, see Alix Cohen (ed.), Kant on Emotion and Value (Palgrave Macmillan, 2014).
} 
discriminating $[\text { unterscheiden }]^{7}$ state of awareness, ${ }^{8}$ but also, according to Kant, an exercise of rational agency thanks to its affective self-consciousness and capacity for responsiveness to a distinctive kind of reasons.

While portraying this picture of pleasure, I will suggest that seeing it clearly requires that we divest ourselves of the following disjunction: either feelings are the noncognitive, passive ways through which we are affected by objects; or they are cognitive states by virtue of the theoretical beliefs they necessarily involve. On my reading of Kant, this disjunction is false. Aesthetic pleasure is neither passive, nor either theoretically or practically cognitive, and yet, it is an exercise of rational agency by virtue of belonging to a domain of rationality that is largely overlooked in the history of philosophy: aesthetic rationality.

My strategy is as follows: in section I, I explain that aesthetic pleasure is rational and analogous to believing for a reason and acting for a reason insofar as, when proper (1) it is an affective mode of being conscious of its ground (namely, of the reasons for feeling it) and thus of itself as called for, (2) its self-conscious nature renders its actuality dependent on reflective endorsement: it is constituted and maintained and thus actually felt insofar as it is affectively recognized — however implicitly—as "to be felt." In section II, I answer the objection that my proposal does not do justice either to the receptive nature of pleasures or to Kant's own view by explaining the kind of activity characteristic of aesthetic pleasure and the distinctive nature of aesthetic reasons.

\footnotetext{
${ }^{7}$ Cf. CPJ, 5:204.

${ }^{8}$ E.g., FI, VIII, FI VIII, 20:231-32, §12, 5:222.
} 


\section{The Rationality of Aesthetic Pleasure}

The distinction between three kinds of pleasures - the pleasure in the agreeable [Angenehm], the pleasure in the good, and the pleasure in the beautiful—is one of the central distinctions in Kant's mature philosophy. Here is one formulation of the difference. The pleasure in the agreeable is a mode of gratification: "Pleasure of this kind, since it comes into the mind through the senses and we are therefore passive with regard to it, can be called pleasure of enjoyment [Lust des Genusses]" (5:292). The pleasure in the good, a pleasure of "self-activity" (5:292) that is grounded in a "command of an absolutely necessitating law" (5:267), is called either "moral" or "intellectual pleasure" (e.g., 5:271, 5:292). And the pleasure in the beautiful, which pleases "in the mere judging [Beurtheilung]" (5:262), is described as a pleasure of "mere reflection" (5:292; Cf. FI, 20:249).

On that account, the pleasure in the agreeable is passive and grounded in (and wholly explained by) the way an object affects the subject's sensory desires and predilections. The pleasure in the good is active and grounded in (and explained by) concepts, most prominently, the concept of the moral law. Aesthetic pleasure is not a pleasure of sensation (e.g., 20:224) — it is not a passive state produced by the way the object sensorily affects the subject. Nor is it a "conceptual pleasure"-a pleasure that is grounded in a concept. What does it mean for it to be a pleasure of "mere reflection" which pleases "in the mere judging"??

\footnotetext{
${ }^{9}$ Melissa Zinkin holds that pleasure is constitutive of reflection insofar as it is that by which reflection is capable of carrying on its distinctive reflective function, which Kant regards as the "holding together" of various representations or of a representation and a cognitive power (e.g., CPJ, FI, 20:211). On her view, pleasure enables this function by being a state that maintains the reflected upon representation in the same state. I agree with her about the necessary relation between pleasure and reflection, but disagree that the reflection at stake is the very same reflection that underlies all cognition since Kant is careful to distinguish between the logical act of reflection that underlies all conception and is an exercise of the understanding,
} 
On the reading I propose here, an essential and central aspect of Kant's way of connecting aesthetic pleasure with reflection and judging concerns its distinctive rationality. I take Kant to suggest that aesthetic pleasure is rational insofar as it is an affective mode of self-consciousness, which is capable of being responsive to reasons for feeling it - reasons that, when the pleasure is proper, both explain why it is felt and justify it. ${ }^{10}$ While reconstructive, I believe that this reading of Kant's notion of aesthetic pleasure is well supported by the text and by his overall view.

Kant suggests that aesthetic pleasure is thusly rational when he claims that judging a beautiful object aesthetically is "merely repeating its [the object's] own claim to everyone's satisfaction" $(5: 282)$. This means that aesthetic pleasure is a mode of responsiveness to what the object calls for or merits. Beautiful objects are such that call for or figure in reasons for feeling a particular kind of feeling. ${ }^{11}$ Not "repeating" beautiful objects' own claims on us would results in a failure of responsiveness to what certain objects merit.

Relatedly, Kant is quoted to claim "we give the beautiful, like the good, our approval."12 The pleasure in beauty is a form of approval because questions about what the object calls for and merits, not what it elicits from us, are internal to aesthetic pleasure. And these questions show the relevance of the rational "why?" question. Even if you cannot answer it, or think there is no answer, the question "why do you like it (the

and the reflection carried on by the power of judgment. Even under the latter, he distinguishes between aesthetic reflection and logical reflection. Thus, Zinkin's view obscures the distinctive nature of the aesthetic kind of rationality and hence the categorical (rather than merely quantitative) difference between aesthetic reflection and judging, on the one hand, and cognitive reflection and judging, on the other hand. See her, "Kant and the Pleasure of Mere Reflection," Inquiry (2012) 55:5, 433-53.

${ }^{10}$ For two other features that render Kant's notion of aesthetic pleasure a rational state, see my "Affective Nihilism or the Relevance of Kant's Transcendental Idealism in Aesthetics" (ms.)

${ }^{11}$ Perhaps, on his view, because of their relation to mindedness in general, namely to the subjective conditions of judging anything at all.

${ }^{12}$ Quoted from students' notes of Kant's lectures, edited as Metaphysik Dohna in LM, 28:676. 
object that you judge to be beautiful)?" is always applicable to aesthetic pleasures so that if the object you like and judge to be beautiful does not merit aesthetic pleasure, one is under rational pressure to re-experience the object and be ready to change affectively. This sense of approval and the relevance of this "why?" question are at the heart of the rationality of aesthetic pleasure.

Kant also emphasizes that aesthetic pleasure is grounded in a priori grounds. Thus, he claims to "have shown that there are also grounds of satisfaction a priori ... even though they cannot be grasped in determinate concepts" (5:347). On Kant's account, when proper, aesthetic pleasure is grounded in grounds that cannot be articulated by general concepts or principles. But the non-generality of these grounds makes them no less reasons. Like reasons for believing and reasons for acting, the grounds of aesthetic pleasures are reasons since, when the pleasure is proper, these grounds both explain and justify it—-they show not only why it is felt but why it should be felt, that is, why it is proper, merited or called for. These grounds thus belong to what Joseph Raz dubbed the "Normative-Explanatory Nexus," a phrase that is meant to explain reasons in terms of the convergence between their explanatory and justificatory functions. ${ }^{13}$ In Kant's, the grounds of aesthetic pleasure are reasons because they are those in light of which aesthetic judgment legitimately and justifiably "determines that pleasure or displeasure must be combined with the representation of the object" (20:229), and does so "a priori by means of [this very same] sensation of pleasure or displeasure" (ibid). ${ }^{14}$

\footnotetext{
${ }^{13}$ See, Joseph Raz, From Normativity to Responsibility (Oxford: Oxford University Press, 2011). I will go back to this briefly in section 2 .

${ }^{14}$ Kant emphasizes that this is done both by means of the feeling and " $a$ priori, through the faculty of cognition (the power of judgment)" (ibid.)
} 
My reading of aesthetic pleasure as rational in this way receives further support

from the discussion of what Kant sometimes regards as the "ground of this pleasure" (e.g., 5:218): what he notoriously calls "the free play of the faculties of cognition with a representation through which an object is given" (e.g., 5:217) or the "harmony of the faculties of cognition" (e.g., 5:218,) and sometimes refers to as the "judging [Beurtheilung] of the object" (e.g., 5:216). ${ }^{15}$

While there is a wide disagreement about the grounding relation between the free harmony of the faculties and aesthetic pleasure, I will restrict myself here to a few remarks that reject the temporal and causal reading of this relation and argue for a rational relation of grounding. After Paul Guyer's understanding of this relation as temporal and causal had reigned in the literature for a long while, it has been under heavy attack during the last two decades. ${ }^{16}$ And for good reasons. Even though in the notorious section 9 of the third Critique, Kant thinks of this grounding relation in terms of "precedence," claiming that, insofar as the harmony of the faculties is the ground of the pleasure, it "precedes" it, there are very strong indications that this precedence cannot be understood as temporal and causal. ${ }^{17}$

\footnotetext{
${ }^{15}$ Kant may seem inconsistent in his descriptions of the a priori ground that both explains and justifies the necessity and universality of aesthetic pleasure for he refers to it not only as the harmony of the faculties but also as "the subjective [but a priori principle] of the power of judgment in general" (5:286; cf. 20:229). I don't think that this is a threatening inconsistency. The air of inconsistency may be resolved by appealing to different levels of grounding and justification. Kant may well be taking the principle of the power of judgment to justify and ground the capacity of aesthetic judgment in general to be the source of a legitimate demand for universal agreement in pleasure. This principle explains why a judgment of a singular beautiful object, made through a feeling of pleasure, can in principle make such a legitimate demand, but it does not ground or justify any particular feeling of pleasure taken in any particular object. The free engagement of the faculties of the understanding and the imagination with a particular object is required to rationally ground and justify any specific case of feeling aesthetic pleasure.

${ }^{16}$ See Guyer, Kant and the Claims of Taste, and, for example, Allison, Kant's Aesthetic Theory, Zuckert, Beauty and Biology, Tinguely, "The Neglected Altenative," and Ginsborg, The Normativity of Nature.

${ }^{17}$ If causality is restricted to efficient causality.
} 
First, while Kant argues that the relation between the mind's faculties and the beautiful object — "the judging of the object"-is the ground of the pleasure, he also claims that aesthetic pleasure is the "determining ground of a judgment which for that reason is called aesthetic" (20:224). He argues further that this pleasure is the "determining ground" that animates the "cognitive powers" (5:222; cf. 5:219), implying that the pleasure and the judging are reciprocally grounding and grounded. If they are, neither one can be said to be temporally prior to, or efficiently causing, the other.

Second, in numerous passages, he stresses that the pleasure and the harmony are not separated mental states, but two sides of the same coin. This is most explicit in the passages where Kant draws an analogy between moral pleasure and aesthetic pleasure as two kinds of pleasure that are grounded a priori. In these discussions, Kant goes as far as to argue against the temporal and causal reading of the relation between aesthetic pleasure and the harmony of the faculties. He emphasizes that, just as the determination of the will to act on the basis of the categorical imperative can in no way be regarded as the efficient cause of moral feeling, but is rather the other side of the same coin, so the harmony of the faculties can in no way be regarded as the efficient cause of aesthetic pleasure, but is rather the other side of the same coin: the two are temporally inseparable aspects of the whole, which is aesthetic judgment:

\footnotetext{
In the critique of practical reason ... we did not actually derive this feeling [of respect] from the idea of the moral as a cause, rather it was merely the determination of the will that was derived from the latter. The state of mind of a will determined by something, however, is in itself already a feeling of pleasure and is identical with it, thus it does not follow from it as an effect ...
} 


\begin{abstract}
Now it is similar with the pleasure in the aesthetic judgment, except that here it is merely
contemplative and does not produce an interest in the object, while in the moral judgment it

is practical. The consciousness of the merely formal purposiveness in the play of the

cognitive powers of the subject in the case of a representation through which an object is

given is the pleasure itself. (5:222; my italics) $)^{18}$
\end{abstract}

But if it neither temporally precedes it nor efficiently causes it, in what sense is the free engagement of the faculties with a beautiful object nonetheless the ground of aesthetic pleasure? I argue that the free engagement of the faculties with a particular object is the rational ground of aesthetic pleasure insofar as it explains and justifies aesthetic pleasure, and insofar as the latter is constituted by being conscious of its fitness to this ground. The free play of the faculties thus "precedes" aesthetic pleasure only in the "rational" order of things. 19

Consider the whole passage:

The consciousness of the merely formal purposiveness in the play of the cognitive powers of the subject in the case of a representation through which an object is given is the pleasure itself because it contains a determining ground of the activity of the subject with regard to the animation of its cognitive powers, thus an internal causality. (5:222)

\footnotetext{
${ }^{18} \mathrm{Cf}$. "As we previously noticed in the Critique of Practical Reason, where the representation of a universal lawfulness of willing must at one and the same time determine the will and thereby also arouse the feeling of resect, as a law contained, and indeed contained a priori, in our moral judgments, even though this feeling could nonetheless not be derived from concepts. In just the same way the resolution of the aesthetic judgment of reflection will display the concept of the formal but subjective purposiveness of the object, resting on an a priori principle, which is fundamentally identical with the feeling of pleasure, but which cannot be derived from concepts" (5:229).

${ }^{19}$ Insofar as aesthetic judging is the rational cause of aesthetic pleasure, and the latter is the consciousness that maintains the former, this judging is also, as Zuckert correctly claims, "transcendentally" prior to it: it is the condition of the possibility of aesthetic pleasure. See, Zuckert, Beauty and Biology, 308-10.
} 
Here Kant claims that the pleasure in the beautiful constitutes and maintains itself by involving consciousness of its ground ("the free play of the cognitive powers"), consciousness which also maintains this ground (is the animating ground of this play). On my reading, this means that the pleasure in the beautiful involves a specific kind of rational causation, ${ }^{20}$ or, differently put, rational structure: aesthetic pleasure is constituted and self-maintained merely by being aware of itself as fitting to its rational ground (to the reasons for feeling it). In this sense, it is rationally caused and maintained - it is an exercise of rationality.

While all pleasures maintain and must, by definition, maintain themselves, as states that are defined by their reproduction (20:230-31, 5:220), the pleasure in the beautiful alone maintains itself merely by being itself a mode of awareness of its ground... ${ }^{21}$

Kant contrasts the "internal causality" that in the passage above he attributes to aesthetic pleasure to the "external causality" of the pleasures in the good and in the agreeable (e.g., 20:231-32). Briefly, the pleasure in the good and the pleasure in the agreeable involve "external causality" because, both in order to be constituted and maintained, they require something that is external to themselves, the production of either

\footnotetext{
${ }^{20}$ I am using the phrase "rational causation" roughly following Eric Marcus (2012), but I don't insist on it. My main point is that a mental state that is constituted and maintained by being conscious of its fittingness to its ground (consciousness of itself as called for or required) exhibits rational structure, or, put differently, is an exercise of rationality. Notice that the pleasure in the good involves both external causality and consciousness of its ground (of the good as good and as deserving pleasure). It may thus also be an exercise of rational causation, but it is different from aesthetic pleasure insofar as it (1) it is not constituted and maintained only by being itself consciousness of its ground, (2) involves the external causality, and exhibits the rationality, of practical reason, and (3) is grounded in different kinds of reasons - practical reasons for acting. I explain these three differences in more detail below.

${ }^{21}$ For Kant, pleasures also maintain the life of the feeling subject (whether animal or human), life which is by definition self-maintaining (e.g., 5:278, $C P r R, 5: 9 \mathrm{n}$ ). I cannot here elaborate on this aspect of pleasure, but only note that I take its explanation to be parallel to the explanation of each pleasure's own selfmaintenance that I am proposing here.
} 
an object (an instance of the same pleasing object) or an action (the action that is required by the concept of either the moral good or the instrumental good) through the efficacy of the will. If I am to continue feeling pleasure in drinking the hot chocolate I am drinking on this cold and crispy winter day, I need to make sure I drink another such cup in similar circumstances. And if I am to continue feeling the pleasure I take in volunteering in the local food bank, I must persist in my endeavor (or perform equivalent virtuous actions). Aesthetic pleasure alone requires nothing other than the mind's engagement with a beautiful object (no external production) in order to be reproduced. In that sense, it is independent of desire (which is roughly what Kant means by "disinterested"). One need neither act in any specific way (say, preserve, curate etc.) nor consume or produce an object in order to feel aesthetic pleasure and in order to maintain it—one needs only to properly judge it and, through this pleasure, be conscious of its ground.

I take it that this way of being constituted and maintained—-merely through a state's awareness of its ground and of itself as fitting this ground - is a mark of rationality. Acting and believing for a reason are marked by the same kind of rational structure.

Intentionally acting is a paradigmatic expression of this rational structure of causation since it (say, intending to kick a ball) necessarily involves a consciousness of its ground. A mere bodily movement (say, a reflex action of kicking a ball, which is a jerk of my leg) does not.

If I am in a state of denial of my competitive ambition and temperament, I may "fail" to know that I kicked the ball (intentionally) to score points and win the game. But when no story of denial, self-deception, or alienation is in the offing, intentional actions involve unmediated consciousness of themselves as "to be done," namely, consciousness 
of the reasons that show the actions to be called for. This does not deny cases in which we are unable to articulate the grounds of our actions. Rather, it means only that our actions are always subject to the question "why?" so that, if the action is shown not to be grounded in good reason, one is under rational pressure to abandon it and revise one's intention.

Belief is another manifestation of this rational causation, and, I claim, so is aesthetic pleasure. Believing a proposition for a reason is a manifestation of rational causation insofar as it involves a consciousness of its ground: an awareness of the corresponding proposition as "to be believed": consciousness of the belief as grounded in the reasons that show it to be called for. Even if I am incapable of articulating my reasons for believing, say, that Paris is in France, my belief is always subject to the question "why?" so that, if the belief is shown to be false-if it is not properly responsive to reasons-I am under rational pressure to abandon and/or revise it.

Like believing and acting for a reason, ${ }^{22}$ aesthetic pleasure is also a mental attitude that, when proper, is rationally constituted and maintained by its awareness of itself as grounded in reasons that show it to be called for (in the relation between the cognitive faculties and the object). ${ }^{23}$ Although most of us are not attuned enough or practiced enough to articulate, let alone to explain the reasons for our aesthetic pleasures, and although aesthetic reasons serve neither as evidence or proofs (as reasons for beliefs)

\footnotetext{
${ }^{22}$ On the important differences between belief, action, and aesthetic pleasure, see section 2.

${ }^{23}$ My proposal involves no claim about the empirical, psychological generation of this pleasure, only about its rational causation, which is categorically different from efficient causation. (See Marcus Rational Causation, Chapter, 4.) That's why I am happy to use the phrase "rational structure" or "rational character" instead of "rational causation." And, in any case, while efficient causes are either change-makers or change-preventers, rational causes do not bring about or prevent changes in a similar way, but are the states of awareness that a certain "rational effect" is called for.
} 
nor as practical justifications, aesthetic pleasure is always subject to the question "why do you feel that?," a question that requires a justifying explanation. And the applicability of this justificatory-explanatory question is explained by the fact that aesthetic pleasure itself is responsive to the question "what is to be felt disinterestedly?"24 Aesthetic pleasure is a stance that is shaped by responsiveness to reasons.

This means that aesthetic pleasure, just like believing and acting for a reason, does not simply happen to be rational: we are not determined to take pleasure in beauty (by any external or psychological force). While our own predilections and physical constitution usually cause us to feel (agreeable) pleasure, say, in certain flavors but not in others, no psychological or physical force determines us to appreciate through pleasure beauty and art. Rather, in judging aesthetically we rationally make up our minds about a beautiful object by being responsive to the question, "what is to be felt (disinterestedly)?”, namely, "what does this object call for or merit?"

Kant writes: "In order to decide [unterscheiden] whether or not something is beautiful, we do not relate the representation by means of the understanding to the object for cognition, but rather relate it by means of the imagination (perhaps combined with the understanding) to the subject and its feeling of pleasure and displeasure" (5:204), and argues that, while judging aesthetically, we decide "the fittingness of the object (its form) ... through pleasure" $(5: 194)$. I take it that he means that aesthetic pleasure is answerable to the question, "what is to be responded to with a (disinterested) feeling?" in and through the actual feeling of this pleasure. We are not psychologically or physically

\footnotetext{
${ }^{24}$ Briefly, "that which is to be felt disinterestedly" (the answer to this question) is an object that calls for or deserves a disinterested pleasure, i.e., aesthetic pleasure. Disinterested pleasure is independent of interest, and interest is a rule-governed connection between pleasure and desire $(M M, 6: 212)$. Accordingly, disinterested pleasure is neither caused by a rule that one formulates on the basis of either a sensory or rational desire, nor does it cause a desire following a rule that one formulates on the basis of this pleasure.
} 
pushed to feel aesthetic pleasure, but "decide" by means of the shared activity of the free imagination, the understanding and feeling whether the pleasure is deserved by the object. $^{25}$

Aesthetic purposiveness is the lawfulness of the power of judgment in its freedom. The satisfaction in the object depends on the relation in which we would place the imagination: namely, that it entertain the mind by itself in free activity. (5:270-71; emphasis (bold) in the original, italics mine)

This all means that aesthetic pleasure is capable of the reflective or affectivelyconscious constitution and self-maintenance I introduced above (capable of "internal causality") because it involves a future-directed commitment to what its object calls for or merits; a commitment, that is, to always be responsive to this object as that which has a "claim on everyone's satisfaction" (5:280-81).

Now, the pleasure in the good also involves commitment to the value of its corresponding action, as either morally or instrumentally good (in light of a further end) and thus as meriting practical pleasure, and it also involves an affective consciousness of a certain power of the mind (though a different power, the faculty of desire in its intellectual guise as practical reason). Yet, (1) whereas the pleasure in the good is responsive to the reasons for feeling it through the cognitive awareness of the concept that demands its corresponding pleasing action, aesthetic pleasure is responsive to the

\footnotetext{
${ }^{25}$ Again, I do not claim that the mental activity of the faculties efficiently causes the pleasure, but that the pleasure is always an affective consciousness of and responsiveness to the relation of the object and the subject.
} 
reasons for feeling it (and thus constitutes and maintains itself) merely through being an affective awareness of them. It thus pleases through "mere reflection." (2) To be reproduced, the pleasure in the good requires the performance of the relevant action: if the action is not performed, there are no reasons to feel the pleasure. Reasons for aesthetic pleasure are reasons for always (positively) evaluating the object through pleasure (whether one engages with it directly again—-"produces it"-or not). Like belief, but unlike the pleasures in the agreeable and in the good, aesthetic pleasure involves a future-directed commitment, independently of the production of any object or action.

Some might think that the reflective and rational character I attribute to aesthetic pleasure fails to do justice to the phenomenology of aesthetic experience. Are aesthetic pleasures really responsive to the question that I introduced? While I do not claim that we in fact ask the question each time we aesthetically like an object, I maintain that we are always subject to this question because, when proper, the pleasure is itself a way of being responsive to that which is to be liked disinterestedly. I claim, then, (1) that we are always subject to the rational question "why" while aesthetically enjoying a beautiful object, but deny both that aesthetic pleasure is the product of any kind of explicit process of reasoning and that we are always capable of fully articulating an answer to this question, ${ }^{26}$ and (2) if the object one disinterestedly likes is shown not to merit disinterested pleasure, one is under rational pressure to re-experience the object and to be open to revise one's pleasure. ${ }^{27}$

\footnotetext{
${ }^{26}$ Similarly, believing for a reason, for example, that the Eiffel tower is in Paris, need not be the explicit conclusion actually drawn from the premises one has for this conclusion.

${ }^{27}$ In the aesthetic case, responding to the rational pressure to revise is not independent of re-experiencing the object for oneself (e.g., 5:284-85).
} 
To see how aesthetic pleasure is shaped by responsiveness to what is to be felt for its object, it is useful, first, to notice that avowing or rejecting aesthetic pleasure, just like avowing or rejecting a belief or intentional action, is not a matter of introspection, but of reconsidering the beauty of the object in its relation to the subject's judgmental activity, and, second, to contrast aesthetic pleasures with agreeable pleasures. I discuss these two points in the rest of the section.

First, being subject to the question, "what is to be felt disinterestedly?" means that aesthetic pleasure involves a consultation with the world that explains what one feels by reference to what is to be felt:

For the judgment of taste consists precisely in the fact that it calls a thing beautiful only in accordance with that quality [Beschaffenheit ] in it by means of which it corresponds with our way of receiving it. $(5: 282){ }^{28}$

That object the form of which ... in mere reflection on it ... is judged as the ground of a pleasure in the representation of such an object—with its representation this pleasure is also judged to be necessarily combined.

According to Kant, aesthetic pleasure is conscious of the "form of purposiveness in the representation through which an object is given to us" (5:221). Accordingly, when I am asked: "Do you really like The Tree of Life?" I don't look inside myself in quest of

\footnotetext{
${ }^{28}$ Judgments of natural beauty, according to Kant, also have their ground "in the object and its shape [Gestalt]" (5:279).
} 
the relevant feeling, but reflect upon the film, possibly watch it again, and attend to its cinematography, the way this cinematography brings out aspects of the story, connects to the soundtrack, and constitutes the distinctive point of view of a child that is essential for a proper engagement with the questions that the film raises about the beginning of life, childhood, parental love, and grace. To answer a question about my pleasure in this film, I have to attend to the film in its relation to the form of my reflecting upon it in this and similar ways, I cannot simply “connect" to my emotions, or reimagine my feelings, as I would likely do if I were asked "Do you really like oatmeal?" Introducing this last question is meant to bring in agreeable pleasures, which I will now contrast with aesthetic pleasures because this contrast sheds light on the responsive character of the latter.

The way I just introduced pleasures in the agreeable may raise a worry: Do I mean to imply that questions about agreeable pleasures are fully answered by introspection?

Well, of course, I may be able to explain why I like oatmeal, and explain it in part by reviewing the properties that the oatmeal has. I do not deny that. ${ }^{29}$ But such explanations are necessarily grounded also in my idiosyncratic likings, inclinations and desires. (I may say that I like oatmeal because its texture and warmth soothes me in the morning, given my specific constitution.) "Between that which pleases merely in the judging and that which gratifies [vergnünt] (pleases in the sensation) there is ... an essential difference. The latter is something that one cannot, like the former, require of everyone" (5:330-31). Explanations of agreeable pleasures are not intersubjectively

\footnotetext{
${ }^{29}$ At the same time, I do not claim that aesthetic pleasure is grounded in the qualities that an object has independently of the mind, but only that it is independent of any private aspect of the mind. For Kant, the relevant ground is the relation between the form of the object and the form of the subject's judgmental activity as expressing the form of the human capacity to judge in general - the form of human subjectivity, not the form of any particular human subject. Yet, the internality of pleasure to each particular judgment of taste indicates that the self is built-in to them, the same self that must autonomously feel pleasure in the object, rather than merely repeat another person's judgment without feeling any pleasure.
} 
sharable as explanations of beliefs, intentional actions, and aesthetic pleasures are. The former do not unfold the reasons why everyone in the same position should be in the same state, and so they are not responsive to the question "what is to be felt?" which is a universal or intersubjective question (a question for everyone in the same situation-not a question about what it may happen to elicit in any specific person). Insofar as they are not responsive to this question, pleasures in the agreeable are not exercises of rational agency.

Another way of putting the difference between aesthetic pleasures and agreeable pleasures (and thus, another way of explaining the rationality of the former) is in terms of desert or merit: "Hence one says of the agreeable not merely that it pleases but that it gratifies. It is not mere approval that I give it, rather inclination is thereby aroused" (5:207). But, "The beautiful is closer than the agreeable to the good because of the freedom that occurs with it... we give the beautiful, like the good, our approval.,"30 Questions about what the object merits, not what it elicits from us, are internal to aesthetic judgment and pleasure, but alien to judgments of the agreeable and their grounding pleasures. And these questions are equivalent to the question about what to judge with a disinterested pleasure. The relevance of this "merit question," is one of the marks of the rationality of aesthetic pleasure.

One might worry that Kant ignores the way in which we regularly revise our agreeable pleasures in light of certain demands, pressures, and norms and take even guilty pleasures to be criticizable and revisable in terms of what is good to do or to feel. But I don't think he does. All that Kant claims is that agreeable pleasures are positioned differently vis-à-vis the world because of their different relation to sharable reasons and

\footnotetext{
${ }^{30}$ Quoted from students' notes of Kant's lectures, edited as Metaphysik Dohna in LM, 28:676.
} 
to questions of desert and merit. Agreeable pleasures are not responsive to a question about what to feel in the same way that aesthetic pleasures are because (1) they are never independent of the person's subjective desires, needs, and inclinations; (2) their actuality does not depend on endorsement (more on that below); and (3) if and when agreeable pleasures are responsive to sharable reasons, standards, or norms, these are external both to the pleasure and to its objects - they usually come in the shape of practical or moral pressures (e.g., 5:331). ${ }^{31}$

Up to now, my explanation of aesthetic pleasure as responsive to the question "what is to be felt disinterestedly?" was part of arguing that it is an exercise of rationality insofar as it is constituted and maintained by consciousness of what makes it called for and of its own propriety. But the responsiveness to this question brings out yet another mark of the rationality of aesthetic pleasure, or, at least, another way of capturing its rationality: aesthetic pleasure is an exercise of rational agency insofar as it is grounded in this kind of consciousness and thus insofar as the basis for actually feeling it is endorsement, not what the object happens to produce in me. While the actuality of agreeable pleasures depends on how subjects are affected by an object, the actuality of aesthetic pleasures presupposes the affective self-consciousness of its propriety to the

\footnotetext{
${ }^{31}$ One might still worry that Kant's way of drawing the distinction obliterates the very idea of food criticism. On one level, this objection seems justified: Kant himself did not fully recognize the possibility of food criticism as an exercise of taste. Nevertheless, I believe that his distinction between agreeable and aesthetic pleasures leaves room for such kind of criticism for I take his view on the matter to imply the following: If, for example, your delight in dark chocolate (as the delight of the food critic) is grounded in an exploration of different kinds of chocolates, tastings, and in a careful reading of expert reviews of different chocolates, so that if others do not appreciate and enjoy the dark chocolates that you do, you would regard it as a failing on their part, then this delight is not agreeable but may well be an aesthetic pleasure. If a pleasure's constitution and maintenance is grounded in endorsing it as a pleasure that ought to be felt by everyone in the same situation, it is not a pleasure in the agreeable, but in the beautiful. Moreover, as value-laden as this contrast may sound, it is meant neither to degrade pleasures in the agreeable nor to undermine their role in human life. Pleasures in the agreeable $d o$ play a significant role in our capacity to live a balanced, full life. But no matter how humanly important pleasures in the agreeable are, and how related they indeed are to the capacity for practical reason, they are categorically different from aesthetic pleasures. Only the latter are rationally, agential states.
} 
object. This relation between endorsement and actuality — the dependence of an attitude on being endorsed as the proper attitude to have — is a central mark of rational agency. ${ }^{32}$

While both intentional action and belief have already been explained along similar lines, I argue that Kant encourages us to recognize that aesthetic pleasure should be understood as an analogous exercise of rational agency.

\section{Response to the Objection of Over-Intellectualism}

One might object to this argument by raising the worry that I emphasize the reflective and responsive nature of aesthetic pleasures at the price of their receptive nature. Even if Kant explains aesthetic pleasures (and displeasures) in terms of their relation to the power of judgment (which he regards as a "high," "intellectual" and "cognitive" power of spontaneity), rather than to sensibility, are they not affective states that belong to our receptive nature?

This objection - fundamentally, the objection of over-intellectualizationsuggests that my proposal conflicts not only with the receptive and affective nature of pleasures, but also with Kant's own view, for, allegedly, it goes against Kant's famous demand of the aesthetic judge to

listen to no reasons and arguments [keine Gründe und kein Vernüfteln], [but] rather believe that those rules of the critics are false or at least that

\footnotetext{
32 In making this claim, I follow Matthew Boyle, "Active Belief," Canadian Journal of Philosophy, 2010 (Supplementary Volume 35): 141. Notice that I do not explain rationality in terms of conceptual shape or conceptual capacities (for that view, see John McDowell, Mind and World, Cambridge, Mass: Harvard University Press, 1996). The picture of rationality portrayed here is more capacious (and perhaps closer to the kind of rationality that McDowell takes to be operative in our "second nature.")
} 
this is not the case for their application than allow that [his] judgment should be determined by means of a priori grounds of proof, since it is supposed to be a judgment of taste and not of the understanding or of reason. $(5: 284-85)$

Treating aesthetic pleasure as a rationally responsive mental attitude may seem to contradict both the letter and the spirit of Kant's Critique.

I respond to this objection along two lines, which I will first list, and then elaborate on: First, although the responsiveness to reasons that I take to be internal to aesthetic pleasure means that it is an active state, the kind of activity that characterizes this pleasure does not imply that it is produced at will, and so it does not contradict the receptive and affective character of pleasure. Second, the reasons to which aesthetic pleasure is responsive are neither evidential, like theoretical reasons for belief, nor practical. They are aesthetic reasons for feeling disinterested pleasure in an object. The rest of the paper is devoted to explaining these points.

First, the reflectively active nature of aesthetic pleasure is compatible with its receptive character since it does not entail that it is produced 'at will.' In contrast to beliefs, judgments, and actions, pleasures are undoubtedly receptive, though Kant suggests that the pleasure in the good and the pleasure in the beautiful are not merely receptive states: they are exercises of our human nature; expressions of ourselves as spontaneous-receptive beings. Receptive as they are, these pleasures are modes of consciousness, responsive either to the demands of reason or to the call of beauty. But this responsiveness is shaped and made possible by a form of activity that is fully 
compatible with their receptive nature, that is, with their not being produced 'at will.' To see that, we need to distinguish between two different kinds of causality, two notions of responsibility, and two distinct senses of activity.

There are at least two different ways in which we may be the causes of our attitudes, and two corresponding ways of having responsibility over them. Intuitively, we seem to be passive with regard to most of our sensations (say, headaches and other pains), and agreeable pleasures (enjoying white but not dark chocolate, flourishing in hot weather but loathing the cold). These mental attitudes seem to force themselves on us - to be generated by causes to which we do not necessarily contribute. Such attitudes are, of course, ours, but ours in being episodes in our psychological histories and mental lives.

The responsibility we have over these attitudes can be called "external" or "thirdperson" responsibility. Richard Moran, who first made the distinction I am introducing here, points out that the attitudes over which I have only external responsibility "are not an expression of $m y$ will, but nonetheless I can exert some influence over them.",33 Surely, sensations and agreeable pleasures may guide our actions, and if we endorse any of them as good to feel and pursue, they might even become, through this reflective endorsement, expressive of our wills. ${ }^{34}$ But, in contrast to beliefs, intentional actions, rationally responsive desires, and (I argue) aesthetic pleasures, sensations and agreeable pleasures are not modes of rational responsiveness to questions about what to do or what to feel. Hence, their actuality does not depend on consciousness of their fitness to their

\footnotetext{
${ }^{33}$ Richard Moran "Frankfurt on Identification," in Contours of Agency, eds. Buss and Overton (Cambridge, Mass: MIT Press, 2002), 200.

${ }^{34}$ That will turn agreeable pleasures into practical, non-pathological pleasures-pleasures in the good. On this transformation, see Engstrom, Form of Practical Reason, 69ff.
} 
ground (or reflective endorsement). Hence, external responsibility is the responsibility we have over attitudes that are not marked by rational agency.

Notice that external responsibility is not tied to attitudes that are not caused 'at will,' and that "causing at will" is neither necessary nor sufficient for what I am going to call "internal" or "agential" responsibility. This is the kind of responsibility we have over attitudes that are exercises of rational agency insofar as they are constituted by being conscious of their fitness to their ground. I can cause myself 'at will' to have a sensation of pain, say by pinching myself, and yet have no internal responsibility over this sensation. No matter how caused, this sensation is not an expression of who I am or what I am committed to, but only an episode I undergo — part of my psychological history, but not part of my identity as a reflective self. If so, causing my attitudes 'at will' is not a sufficient condition for internal responsibility. But nor is it a necessary condition. We need not assume that beliefs, and "responsive desires" (desires that are not merely the result of, say, hunger or fatigue, but are shaped by a sense of what is good) have to be formed 'at will.' The kind of activity relevant for these attitudes—-free rational endorsement—is sufficiently different from willing, choosing, or deciding, but is proper for explaining the subject's taking the state to be an attitude she is committed to. We are agentially responsible for an attitude, which is an expression of who we areparadigmatically, a belief, an action, a "rationally responsive" desire, less paradigmatically an emotion, a concern, and, I add, aesthetic pleasure - not insofar as it is caused 'at will,' but insofar as the attitude is subject to a "why" question, or, as Kant puts it, insofar as it is a matter of 'approval. ${ }^{35}$

\footnotetext{
${ }^{35}$ Notice that I need not be able to give the exact reason for acting that way, having this desire, or feeling this pleasure in order to be thusly responsible for it. As G. E. M. Anscombe argues, answers like, "for no
} 
If this is right, then agential responsibility is neither a matter of having control over an attitude, nor is it a matter of producing it. Rational and responsible agency over a state is compatible with us not having external control over the state-with us not causing it 'at will.' And so, the receptive nature of aesthetic pleasure does not prevent it from being an exercise of rational agency. Aesthetic pleasure can, without contradiction, be both a receptive and rational attitude. The requirement on the agential nature of an attitude is that its actuality depend on its endorsement as an attitude to have. And, as I suggested earlier, the actuality of aesthetic pleasure does depend on its affective, selfconscious endorsement. Feeling such a pleasure is being responsive to beauty as that which "has a claim on everyone's satisfaction." And so, although aesthetic pleasure is not produced 'at will,' it is characterized by the kind of activity that is necessary and sufficient for any attitude to be a rationally free attitude.

It is time to turn to the second line of response to the objection I am treating on these pages, the line of response that distinguishes aesthetic rationality from theoretical rationality and from practical rationality.

I do not suggest that one can offer the reasons one is responsive to when properly making an aesthetic judgment as evidence for one's judgment, or as a universally accessible and objective proof of the propriety of one's pleasure. This is not Kant's view, and, I think, not the right view to hold. Reasons for aesthetic pleasure are neither evidential nor practical, but aesthetic through and through. And yet, like belief and action, this pleasure is also subject to the question 'why.' The main point behind my

particular reason," or "now, why did I do this/feel this/desire this?" are compatible with the relevance of the rational "why?" question, and so they need not exclude the attitude from the domain of agential responsibility. This relevance, but not recognition of actual reasons, is required for the kind of rationality, responsibility and agency I am discussing here. See, Intention (Cambridge, Mass.: Harvard University Press, 1957). 
insistence that aesthetic pleasure is responsive to this question is that it is not a product of brute receptivity, but an exercise of rationality insofar as it is constituted and maintained through self-consciousness of propriety and aptness; insofar as its actuality depends on endorsement. $^{36}$

But being rational in that way does not render aesthetic pleasure a "cognitive" act in the Kantian sense of the term "cognitive," only an act of rational agency. "Pleasure is . . . a basic property ... which cannot be reduced to anything, thus not also to the faculty of cognition" (LM, 28:674-75). For Kant, this means that aesthetic pleasure is not supported by conceptual representations, general principles, reasons for believing, or reasons for acting. Yet, it is part of the space of reasons. For aesthetic pleasures are nonetheless explained and justified by aesthetic reasons. ${ }^{37}$ What are these?

One might think that the difference between aesthetic reasons, on the one hand, and theoretical and practical reasons, on the other, is that aesthetic reasons can only provide likelihood but no guarantee. Those reasons, the line goes, do not entail the aesthetic goodness of the object in question. ${ }^{38}$ It may be maintained, for example, that Cate Blanchett's fine acting explains and justifies, but does not guarantee, the excellence of Woody Allen's film Blue Jasmine, and so, allegedly, is no reason for aesthetically liking it.

\footnotetext{
${ }^{36}$ I agree with Moran, "Frankfurt," 211-212, that no pleasure, not even pleasures in the agreeable, are a matter of brute receptivity in the same way that sensations are. But given his admission that an agreeable pleasure may well survive the realization that it is not worthy, and that it is "not being based on reasons," I suspect that Moran would agree with me that agreeable pleasures are not exercises of rational agency in the way that aesthetic pleasure are.

${ }^{37}$ I take it that this is partly why Kant has come to believe that the faculty of pleasure and displeasure has a high, intellectual part- the power of judgment - that endows this faculty with a priori principles.

${ }^{38}$ E.g., Frank Sibley, Approach to Aesthetics: Collected Papers on Philosophical Aesthetics (Oxford:

Oxford University Press, 2001), 40.
} 
But this way of differentiating the three kinds of reasons is mistaken. For one thing, talk about guarantee and entailment is as misplaced in the practical domain of reasons as it is in the aesthetic domain. The end of being benevolent, for example, does not entail my taking care of my neighbor's child during her mourning over her husband even if it is a reason for doing so, and the aim of completing my paper is a reason for my sitting at the computer right now, even though the former does not guarantee the latter.

Talk about likelihood, guarantee and certainty is misplaced in the aesthetic and the practical domains on normative and logical grounds because such a talk is a talk about proofs or evidence. And proofs and evidence support beliefs, neither actions nor aesthetic judgments and pleasures. An expression of your belief that an object is beautiful, Kant insists, is not an aesthetic judgment, but a theoretical, or as he often refers to it, a "logical judgment" (e.g., CPJ, 5:284). If you judge, "The Tree of Life is an excellent film," and explain your judgment and the pleasure it expresses by claiming, "I haven't seen the film, but A.O. Scott wrote a raving review of the film," your judgment is not an aesthetic judgment, but a theoretical judgment: an expression of your belief that the film is good, backed up by the evidence of experts. If Kant is right, aesthetic judgment is not such an expression of belief but an expression of a disinterested pleasure that everyone is to feel for the object; it is an expression of the responsive liking that I described above. And since it is not an expression of belief, aesthetic judgment is not backed up by proofs or by any reasons for believing that the object is beautiful.

Nor is it supported by reasons for taking some action with regard to the object. If you tell me that The Tree of Life is good because it can improve one's relationship with one's parents, you have neither explained nor justified your aesthetic appreciation of the 
film, but expressed a practical judgment supported by reasons for acting a certain way: reasons to go and watch the film, not reasons to aesthetically like or appreciate it.

So what supports aesthetic judgment? In brief, rather than reasons for believing or acting, aesthetic reasons are reasons for (disinterestedly) feeling, or more precisely, for appreciating, where appreciating stands for the affective, imaginative and intellectual activity that Kant calls 'aesthetic judgment:' the activity of feeling disinterestingly in accordance with the free harmony of the imagination and the understanding in responsiveness to the relevant object. If we merely believe that the film is great, but don't feel the appropriate kind of pleasure, we may be responsive to theoretical reasons, but not to any aesthetic reasons, and so we fail to appreciate the object, that is, to aesthetically judge it. Making an aesthetic judgment is being responsive to the object's claim to a universal pleasure (5:280-81) through this very pleasure, and, thus, it is a mode of responsiveness to the reasons in which this claim figures in, namely, reasons for feeling a specific kind of pleasure.

Notice that this affective rational responsiveness to (or appreciation of) a beautiful object is also an affective responsiveness to a certain parts-wholes relationship. To judge beauty aesthetically, we must appreciate (rather than believe) - through our own affective engagement with the object— the necessity of the unity of the "beauty-making features" of the object for the beauty of this object as a whole (even if it is not necessary for the beauty of every object of its kind). And we appreciate that when we appreciate the reciprocal relation between the object as a whole and its "beauty-making-parts" by liking the whole and the parts disinterestedly. ${ }^{39}$ Aesthetic reasons, then, have a holistic shape,

\footnotetext{
${ }^{39}$ On this reciprocal part-whole relation, see my "A Tale of Two Faculties," British Journal of Aesthetics, 51.4(2011): 415-436.
} 
which is to be felt or appreciated. Appreciating the fitness or discord between the parts of an object and the object as a whole is a matter of feeling. And so being responsive to aesthetic reasons is not feeling pleasure on the basis of believing that pleasure is called for, but feeling that the pleasure that one actually feels is called for. As I explained above, when proper, aesthetic pleasure is the affective mode through which we are responsive to what is to be felt disinterestingly. And since it is also conscious of its own propriety, aesthetic pleasure is both object-oriented and self-oriented.

Accepting the distinctive reasons for appreciating as reasons is challenging, but the challenge is worthy. For the assumption that rationality has the form of theoretical rationality - that it is disjunctively either deductive or inductive and includes only reasons for believing - is a false assumption. A more fruitful way of thinking about rationality is in the terms I introduced in section I. Even if reasons for aesthetic appreciation are often hard to articulate, aesthetic pleasure is responsive to reasons because of the dependence of its actuality on endorsement, and because of its being affectively conscious of its propriety to its ground. In contrast to answers about agreeable pleasures, the answer to the question "why do you (aesthetically) like it?" is "because it is beautiful," which means, for Kant, "because it merits a disinterested pleasure (from everyone)..$^{40}$

Accordingly, aesthetic pleasures and judgments are responsive to reasons, but to specifically aesthetic reasons. The main distinguishing mark of aesthetic reasons is that

\footnotetext{
${ }^{40}$ Again, based on what Joseph Raz titled the "explanatory-normative nexus," we can also say that an exercise of rational agency is one grounded in normative reasons, where normative reasons explain by being normative: they explain an attitude (e.g., belief, intentional action, emotion) insofar as they not only prompt but also guide it through the agent's rational awareness of them as reasons for this attitude. Aesthetic pleasure is responsive to reasons on this account too. See, From Normativity to Responsibility.
} 
they are neither reasons for believing nor reasons for acting but for feeling a distinctive kind of disinterested pleasure that purports to reveal its object and its own propriety.

One of the virtues of this proposal is that it seems to do justice to the character of aesthetic discourse. It explains why we often ask for and give reasons for our aesthetic likings. And it suggests a way of thinking about the dependence of aesthetic judgments and the rational explanations of our likings on individual appreciations. It explains, in other words, why it is not enough to say "the performance was brilliant because it was so precise" independently of liking the individual performance as brilliant in the way that it is. For another person, consulting her experience, may say that it is exactly this precision that made the performance sound mechanical and lacking in passion- - her dislike of the performance is her finding the precision a demerit here. If I am right, then the fact that aesthetic judgments and their rational explanations do not compel anyone else to agree with me independently of the person's coming to appreciate what I do through her own affective experience may look less puzzling. On this Kantian-inspired account, finding the piece's precision to be either a merit or demerit is (i.e., can be achieved only in and through) one's own experience of pleasure or displeasure. ${ }^{41}$

And so, I insist that, while aesthetic pleasure is rational, it is an exercise of a form of rationality that is categorically different from the more familiar theoretical and practical forms of rationality. Aesthetic pleasure is an exercise of aesthetic rationality. ${ }^{42}$

\footnotetext{
${ }^{41}$ This means also that my proposal explains why aesthetic explanations are not proofs or whatever we call the support of an action, but rational guides of appreciation. Cf. James Shelley "Critical Compatibilism" in Knowing Art, eds. Matthew Kieran and Dominic Mclver Lopes (Dordrecht: Springer, 2007), 125-36.

Following Sibley, though, Shelley regards them as "guides to perception," while I regard them as rational guides to appreciation, which is an expression of liking.

${ }^{42}$ This paper greatly benefited from discussions with audiences at Auburn University, The University of Chicago and Tel Aviv University.
} 